\title{
Early Onset and Differential Temporospatial Expression of Melanopsin Isoforms in the Developing Chicken Retina
}

\author{
Daniela M. Verra, ${ }^{1}$ Maria Ana Contín, ${ }^{1}$ David Hicks, ${ }^{2}$ and Mario E. Guido ${ }^{1}$
}

Purpose. Retinal ganglion cells (RGCs) expressing the photopigment melanopsin (Opn4) display intrinsic photosensitivity. In this study, the presence of nonvisual phototransduction cascade components in the developing chicken retina and primary RGCs cultures was investigated, focusing on the two Opn 4 genes: the Xenopus (Opn $4 x$ ) and the mammalian (Opn $4 m$ ) orthologs.

Methods. Retinas were dissected at different embryonic (E) and postnatal (P) days, and primary RGC cultures were obtained at E8 and kept for 1 hour to 5 days. Samples were processed for RT-PCR and immunochemistry.

Results. Embryonic retinas expressed the master eye gene Pax6, the prospective RGC specification gene Brn3, and components of the nonvisual phototransduction cascade, such as Opn $4 m$ and the $G$ protein $\mathrm{q}(G q)$ mRNAs at very early stages (E4-E5). By contrast, expression of photoreceptor cell markers (CRX, red-opsin, rhodopsin, and $\alpha$-transducin) was observed from E7 to E12. Opn $4 \mathrm{~m}$ protein was visualized in the whole retina as early as E4 and remained elevated from E6 to the postnatal days, whereas Opn $4 \mathrm{x}$ was weakly detected at E8 and highly expressed after E11. RGC cultures expressed $G q$ mRNA, as well as both Opn 4 mRNAs and proteins. Opn $4 \mathrm{~m}$ was restricted exclusively to the GC layer at all ages, whereas Opn $4 x$ was limited to the forming GC layer and optic nerve at E8, but by E15, its expression was mostly in Prox1(+) horizontal cells.

Conclusions. The early expression onset of nonvisual phototransduction molecules could confer premature photosensitivity to RGCs, while the appearance of Opn $4 x$ expression in horizontal cells suggests the identification of a novel type of photosensitive cell in birds. (Invest Ophthalmol Vis Sci. 2011; 52:5111-5120) DOI:10.1167/iovs.11-75301

From the ${ }^{1}$ Departamento de Química Biológica, CIQUIBC (Centro de Investigaciones en Química Biológica de Córdoba), Facultad de Ciencias Químicas, Universidad Nacional de Córdoba CONICET (Consejo Nacional de Investigaciones Científicas y Técnicas), Córdoba, Argentina; and the ${ }^{2}$ CNRS (Centre National de la Recherche Scientifique) UPR 3212, INCI (Institut des Neurosciences Cellulaires at Intégratives), Strasbourg, France.

Supported by Agencia Nacional de Promoción Científica y Técnica (FONCyT, PICT 2004 No. 967, PICT 2006 No. 898), Consejo Nacional de Investigaciones Científicas y Tecnológicas de la República Argentina (CONICET), Secretaría de Ciencia y Tecnología de la Universidad Nacional de Córdoba (SeCyT-UNC), and Ministry of Sciences and Technology of Córdoba.

Submitted for publication March 9, 2011; revised April 15, 2011; accepted April 28, 2011.

Disclosure: D.M. Verra, None; M.A. Contín, None; D. Hicks, None; M.E. Guido, None.

Corresponding author: Mario E. Guido, CIQUIBIC, Departamento de Química Biológica, Facultad de Ciencias Químicas, Universidad Nacional de Córdoba-CONICET, Ciudad Universitaria, 5000 Córdoba, Argentina; mguido@fcq.unc.edu.ar.
T $\mathrm{n}$ vertebrates, a third group of retinal photoreceptors has recently been identified as intrinsically photosensitive retinal ganglion cells (ipRGCs). ${ }^{1,2}$ These cells are responsible for conveying photic information to the brain concerning ambient illumination conditions and regulate distinct non-image-forming (NIF) tasks (e.g., synchronization of circadian clocks and pupillary light reflexes). ${ }^{3-5}$ Likely evolved from a common ancestor with rhabdomeric photoreceptors of invertebrates, these ipRGCs express the photopigment melanopsin (Opn4), ${ }^{1,2,6}$ an opsin closely related to the invertebrate Gq-coupled visual pigment. ${ }^{2,3,7-11}$ Moreover, based on data from specification markers, horizontal and amacrine cells in the inner retina could be considered sister cells of ipRGCs. ${ }^{12,13}$

The biochemical events of phototransduction operating in the ipRGCs involve the activation of phospholipase C (PLC) ${ }^{8,10,14}$ and of the phosphoinositide (PIP) cycle $^{15}$ in a manner similar to that of the invertebrate photocascade..$^{8-10,14,15}$

Vertebrates have evolved two separate opn4 genes: Opn $4 x$ (also named Opn $4-1^{16}$ or $O p n 4 a^{17}$ ) and $O p n 4 m$ (also named $O p n 4-2^{16}$ or $O p n 4 b^{17}$ ) which are orthologs of the nonmammalian and mammalian vertebrate genes, respectively. ${ }^{10,11,16-20}$ In the chicken retina, different laboratories have reported the expression of Opn 4 genes in cells of the outer nuclear (ONL), inner nuclear (INL), and ganglion cell (GCL) layers. ${ }^{10,11,16-20}$ These two genes encode at least five different isoforms, two of which show blue-light sensitivity. ${ }^{16}$ Moreover, detectable expression of both melanopsin transcripts (Opn $4 x$ and $O p n 4 m$ ) has been observed in retinas of GUCY1* chickens, an avian model of blindness lacking functional rod and cone photoreceptors that shows persistent light responses in diverse NIF tasks. ${ }^{5}$ GUCY1* birds are clinically blind since hatching, even though their retinas are morphologically normal during the first weeks and only become degenerated after 2 to 3 months. ${ }^{5}$

The goal of the current work was to investigate the onset of expression of the nonvisual phototransduction machinery during development in the embryonic chicken retina and in isolated RGCs. To this end, we first examined the expression of Opn $4 \mathrm{x}$ and Opn $4 \mathrm{~m}$ at the mRNA and protein levels in whole developing retina at different embryonic stages, as well as in immunopurified RGC cultures from embryonic day (E) 8 retinas. Second, we investigated the cellular localization of Opn 4 proteins in the retina during development as well as in the mature retinas of wild-type (WT) and blind birds (GUCY1*).

\section{Materials AND Methods}

\section{Materials}

All reagents were of analytical grade. The secondary antibodies used for immunocytochemistry (ICC) and immunohistochemistry (IHC) were Alexa Fluor 488 goat anti-rabbit and Alexa Fluor 546 goat anti-rat IgG (dilution 1:1000; Invitrogen-Molecular Probes, Eugene, OR). Propidium iodide and DAPI were from Sigma-Aldrich (St. Louis, MO). 
Aqueous mounting medium (FluorSave) was from Calbiochem (San Diego, CA). The secondary antibodies used for WB were goat antirabbit $800 \mathrm{CW}$ and goat anti-rat $800 \mathrm{CW}$ (IRDye, dilution 1:25,000) from Li-COR (Lincoln, NB). Protease inhibitor and other biochemical reagents were from Sigma-Aldrich; B-27 supplement 50× was from Invitrogen-Gibco (Grand Island, NY). $\alpha$-Tubulin ( $\alpha$-Tub) was detected by the mouse monoclonal DM1A antibody (1:1000 for WB; SigmaAldrich). The primary antibody against chicken Opn $4 \mathrm{x}$ was raised in rabbit using the specific Opn4x peptide 1: RQKRDLLPDSYSCSEE. ${ }^{21}$ The antibody against the chicken Opn $4 \mathrm{~m}$ was raised in rat and generated with the specific Opn $4 \mathrm{~m}$ peptide: CKHGNRELQKQYHR ${ }^{20}$ (BioSynthesis Inc., Lewisville, TX).

\section{Chicken Thy-1, Antisera Preparation, and Purification}

Preparation of anti-chicken Thy-1 sera was performed by Bio-Synthesis, Inc. They synthesized the NH2-KNITVIKDKLEKC-OH peptide sequence conjugated with KLH and then immunized two rabbits. After 6 weeks they bled the rabbits and tested the serum by ELISA. A total of 100 to $150 \mathrm{~mL}$ of crude serum with five boosts and four bleeds were purified by affinity column purification.

\section{Primary Cultures of Embryonic RGCs}

RGCs from E8 neural retinas dissected in ice-cold $\mathrm{Ca}_{2}-\mathrm{Mg}_{2}$-free Tyrode's buffer containing $25 \mathrm{mM}$ glucose were immunopurified with the anti Thy-1 antibody as described. ${ }^{10,15,22}$ The cell cultures were highly enriched in RGCs ( $>93 \%$ according to different RGC markers) $)^{10,15,22}$ and incubated from 1 hour to 5 days at $37^{\circ} \mathrm{C}$ under constant $5 \% \mathrm{CO}_{2}$-air flow in a humid atmosphere.

All experiments were performed in accordance with the ARVO Statement for the Use of Animals in Ophthalmic and Vision Research, approved by the local animal care committee (School of Chemistry, Universidad Nacional de Córdoba; Exp. 15-99-39796).

\section{Preparation of Optic Nerve and Outer Plexiform Layer Samples}

After decapitation, both eyes were dissected from the head, cutting at the level of the optic nerve (ON) head. The skull was then opened carefully to expose the ON still attached to the brain, and approximately 2 to $3 \mathrm{~mm}$ from each side (until the optic chiasma) was dissected and either fixed for antibody labeling or homogenized in PBS for Western blot analysis (see respective sections). Eyes were opened at the iris, and the lens and vitreous humor were removed. The eye cups were rinsed twice in $4 \mathrm{~mL}$ of cold $0.25 \mathrm{M}$ sucrose, immediately frozen in liquid $\mathrm{N}_{2}$, and lyophilized overnight at $-40^{\circ} \mathrm{C}$. Highly enriched preparations in the outer plexiform layer (OPL) were obtained as previously described. ${ }^{23}$ Briefly, each lyophilized retina was sandwiched between adhesive tape attached to the RGC and retinal pigment epithelium (RPE) surfaces, After the upper piece of adhesive tape with RPE attached was removed, another piece of tape was applied to the remaining retina, and a different layer was removed, bound to the uppermost tape. This process was repeated successively, such that the RPE (dark gray color) was attached to the first piece of tape, the photoreceptor cell (PRC) layer (orange color) to the second and third tapes, and the OPL to the fourth and fifth tapes. OPL samples were then homogenized in PBS for Western blot analysis (see below).

\section{Immunohisto(cyto)chemistry}

Embryonic chick eyes were dissected from the head in cool PBS; the cornea, lens and pectens discarded; and the posterior eye cup fixed in $4 \%$ paraformaldehyde in phosphate-buffered saline (PBS) overnight at $4{ }^{\circ} \mathrm{C}$; ON was fixed in the same way, and cultured cells were fixed for 30 minutes (4\% paraformaldehyde in PBS). Eye cups and ON were cryoprotected in sucrose and sectioned by cryostat. Sections and fixed coverslips were washed in PBS, treated with blocking buffer (PBS
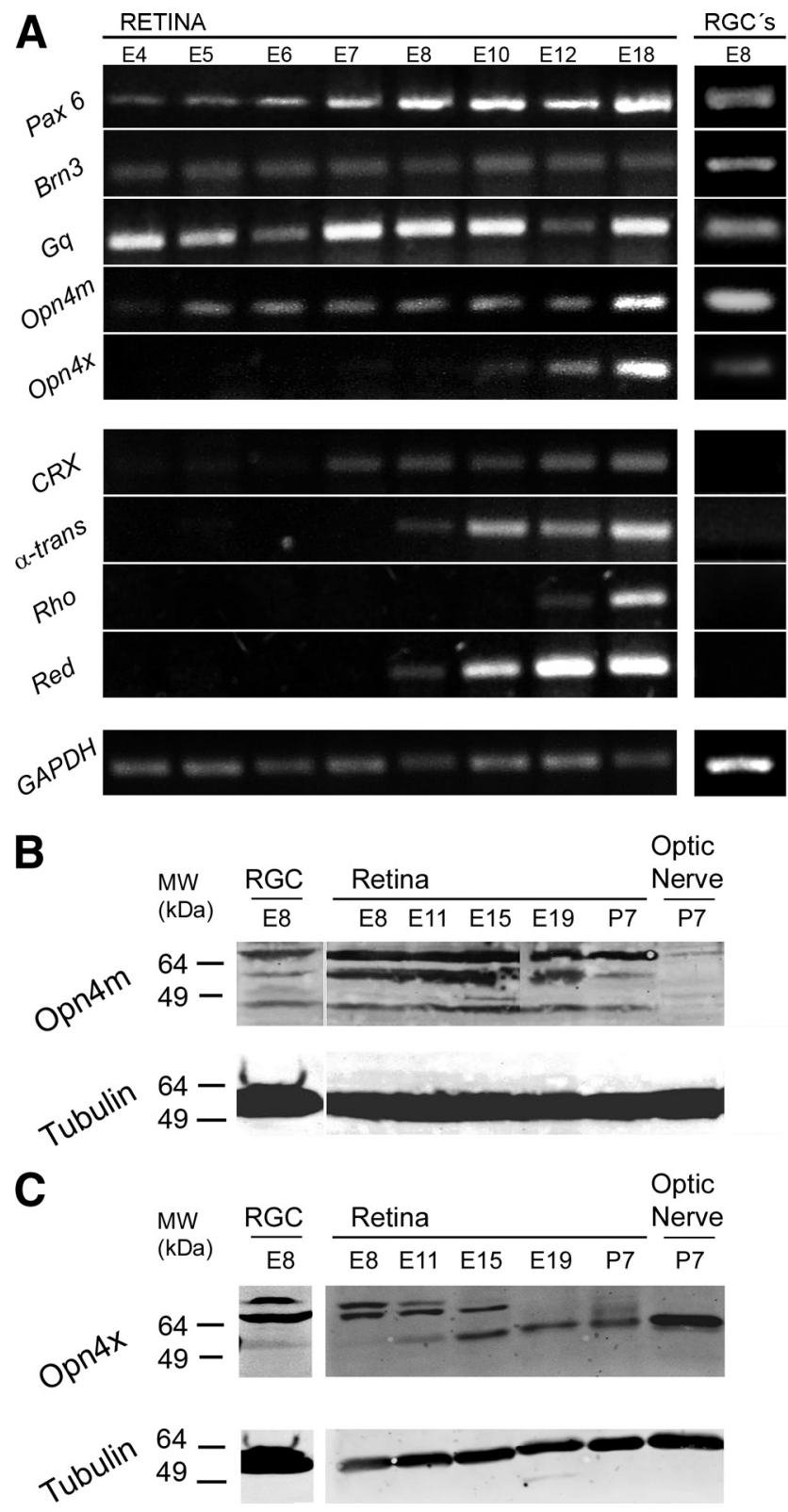

FIGURE 1. Temporal profiles of gene expression in the developing chicken retina. (A) Analysis of mRNA expression in the whole chicken retina from E4 to E18 and in primary cultures of E8 chicken RGCs (RGC-E8). Chicken embryonic retinas were dissected from E4 to E18, and RGCs were immunopurified from E8 retina and cultured for 1 hour. mRNA expression was assessed by RT-PCR from RGC-E8 and retinal samples collected from E4 to E18. Retinal cell specification markers: Pax-6, Brn3, and CRX. G proteins: $\alpha$-transducin ( $\alpha$-trans) and q $(G q)$. Photopigments: melanopsin (Opn4) isoforms (mammalian orthologue Opn $4 m$ and Xenopus orthologue Opn $4 x$ ), rhodopsin (Rbo), and red cone opsin (Red). GADPH, housekeeping gene. Left: gene expression in developing whole retina; right: gene expression in RGC-E8 cultures. Results shown are representative of those in four independent experiments. Expression of Opn4m (B) and Opn 4x (C) proteins was detected in the whole retina from E8 to E19 and P7, in the $\mathrm{ON}$ at $\mathrm{P} 7$, and in primary RGC cultures at E8 (RGC). Protein assays were performed by WB of $50 \mu \mathrm{g}$ protein for each sample and specific primary antibodies against Opn $4 \mathrm{~m}, \operatorname{Opn} 4 \mathrm{x}$, and $\alpha$-Tubulin (Tubulin). For Opn $4 \mathrm{~m}$, immunoblots showed three bands of $\sim 48,62$, and 65 to $70 \mathrm{kDa}$, whereas for Opn $4 \mathrm{x}$, there were three bands of $\sim 55$ to 60,65 , and $70 \mathrm{kDa}$. Results shown are representative of three blots from independent experiments. 
supplemented with $0.1 \% \mathrm{BSA}, 0.1 \%$ Tween 20 , and $0.1 \% \mathrm{NaN}_{3}$ ) and incubated with the different antibodies: anti-chicken Opn4x (1:1000 at $4^{\circ} \mathrm{C}$ for 24 hours) and anti-chicken Opn $4 \mathrm{~m}\left(1: 200\right.$ at $4^{\circ} \mathrm{C}$ for 24 hours), together with anti-rhodopsin (Rho4d2, 1:1000), ${ }^{24} \mathrm{ON}$ bipolar cell marker $(115 \mathrm{a} 10 ; 1: 100)^{25}$, anti-neurofilament monoclonal antibody (8A1; 1:1000; Santa Cruz Biotechnology, Santa Cruz CA) or anti-cone $\alpha$-transducin (GaT2, 1:500; Santa Cruz Biotechnology). They were then rinsed in PBS and incubated with goat anti-rabbit IgG Alexa Fluor 488 (Opn4x) and goat anti-mouse IgG Alexa Fluor 546 (monoclonal antibodies), or goat anti-rat IgG Alexa Fluor 488 (Opn4m; 1:1000) for 1 hour at room temperature (RT). In some experiments, samples were incubated with propidium iodide $(0.05 \mathrm{mg} / \mathrm{mL})$ or DAPI $(300 \mathrm{nM})$. For the double-immunolabeling experiments with Opn $4 \mathrm{x}$ and Prox1 (Abcam Ltd., Cambridge, MA) rabbit polyclonal antibodies, the sections were first incubated in Opn4x (1:2000) overnight, washed and incubated in goat anti-rabbit IgG-Alexa Fluor 488 for 1 hour at RT, washed again, refixed in $3 \%$ paraformaldehyde $+4 \%$ sucrose in PBS for 1 hour, washed and permeabilized with $0.1 \%$ Triton X-100, and reblocked in saturating buffer supplemented with $2 \%$ horse serum, 3\% BSA, and $0.05 \%$ Triton X-100 for 2 hours at RT. The sections were then incubated overnight at $4^{\circ} \mathrm{C}$ in Prox 1 (1:1000) in the same saturation buffer, washed, and treated with secondary goat anti-rabbit IgG-Alexa Fluor 546 for 1 hour at RT. Slides and coverslips were finally washed thoroughly and viewed by confocal microscopy (FV1000; Olympus, Tokyo, Japan).

\section{Western Blot Analysis}

Homogenates of whole chicken retinas from embryonic or postnatal days, ON samples, OPL preparations, and primary RGC cultures resuspended in PBS buffer containing protease inhibitors were processed for WB by using published procedures. ${ }^{26}$ Homogenates were resuspended in sample buffer and separated by SDS-gel electrophoresis on $10 \%$ polyacrylamide gels ( $50 \mu \mathrm{g}$ total protein/lane), transferred onto nitrocellulose membranes, blocked for 1 hour at RT with 5\% skimmed milk in PBS, and incubated overnight at $4^{\circ} \mathrm{C}$ with specific antibodies in the incubation buffer (2.5\% skimmed milk and $0.1 \%$ Tween 20 in PBS). The membranes were washed three times for 15 minutes each in washing buffer ( $0.1 \%$ Tween 20 in PBS) and incubated with the corresponding secondary antibody in incubation buffer during 1 hour at RT followed by three washes with washing buffer for 15 minutes each. For Li-COR IRDye antibodies, the membranes were scanned (Odyssey IR Imager; LI-Cor Biosciences). After incubation with Opn 4 antibodies, the membranes were stripped with $\mathrm{NaOH} 0.5 \mathrm{M}$ and incubated in blocking buffer containing $\alpha$-tubulin antibody.

\section{RNA Isolation and cDNA Synthesis}

Total RNA from RGC cultures was extracted according to the method of Chomczynski and Sacchi, ${ }^{27}$ using a kit for RNA isolation (TRIzol;
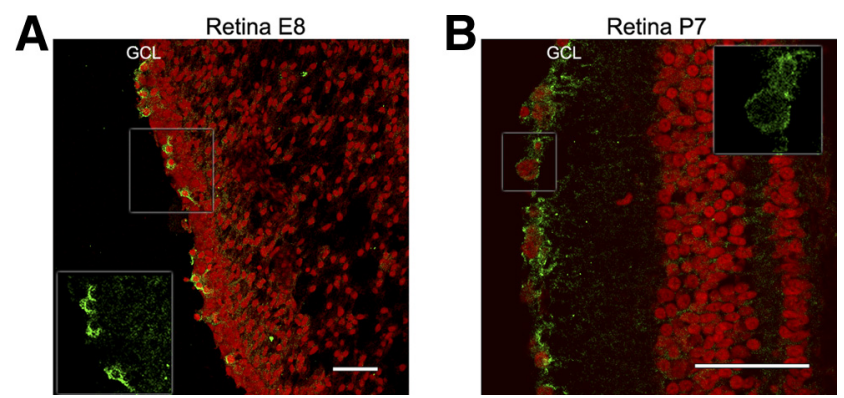

FIGURE 2. Immunohistochemistry for Opn $4 \mathrm{~m}$-like protein in the chicken retina at $\mathrm{E} 8$ and $\mathrm{P} 7$. Retinal sections were immunolabeled for Opn $4 \mathrm{~m}$ (green) and propidium iodide (red) and visualized by confocal microscopy with a specific primary antibody at $20 \times$ and $40 \times$ magnification. Insets: positive immunoreactivity was visualized in cell somas for Opn $4 \mathrm{~m}$ in both the forming and mature GCL, as seen at E8 and P7, respectively. Scale bar, $20 \mu \mathrm{m}$.

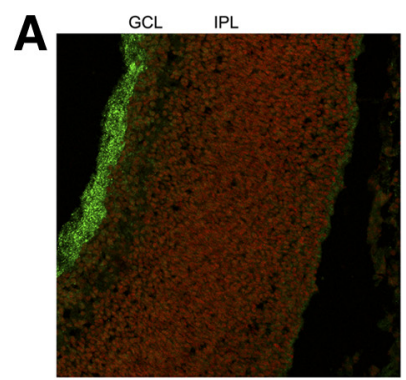

B
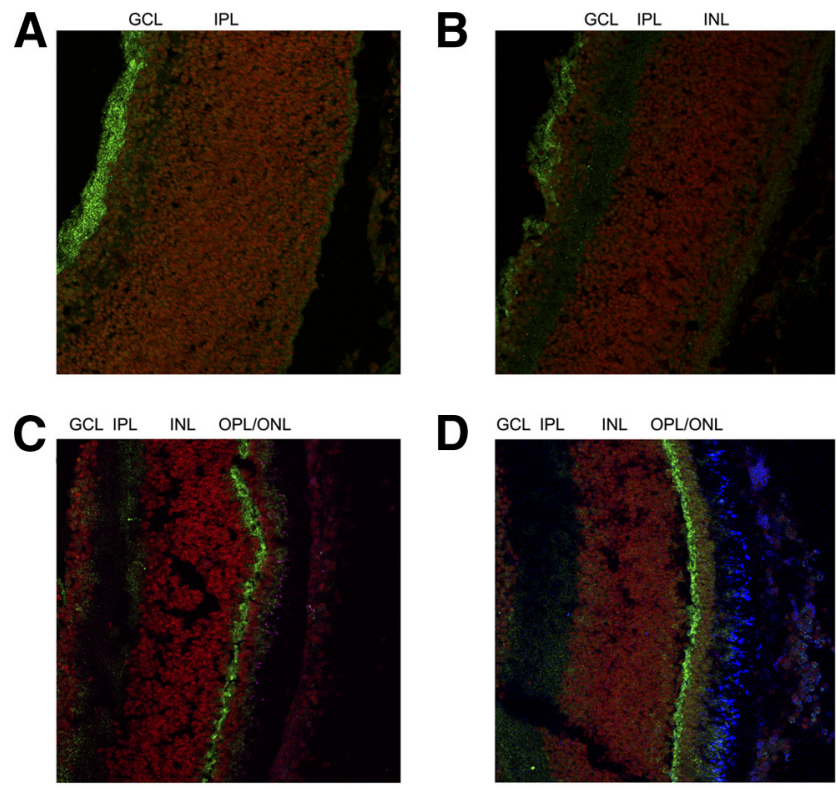

D
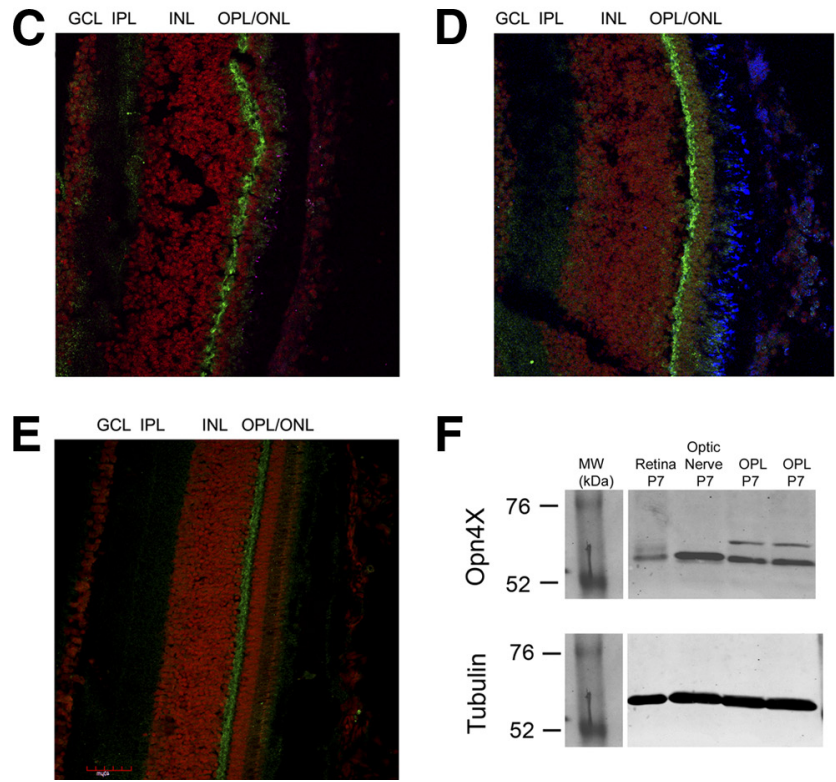

$\mathbf{F}$

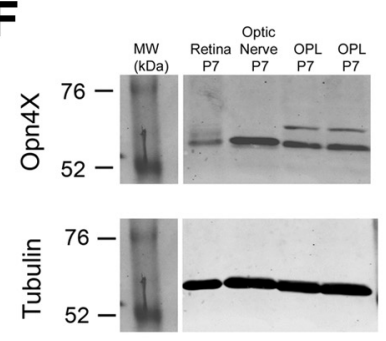

FigurE 3. Immunochemistry for Opn $4 x$-like protein in the chicken retina during development. (A-E) Retinal sections were immunolabeled for Opn4x (green), rhodopsin (blue), and propidium iodide (red nuclear staining) and visualized by confocal microscopy with specific primary antibodies at $40 \times$ magnification. Positive immunoreactivity was visualized for Opn $4 \mathrm{x}$ in the axonal fibers of the forming GCL at E8 to E11 (A, B) and in the OPL at E15 to E19 and P7 (D-F). Positive immunoreactivity for rhodopsin seen at E19 (D) demarks the outer segments of the rod PRCs. Scale bar, $40 \mu \mathrm{m}$. (F) Expression of Opn $4 \mathrm{x}$ protein in the whole retina, the ON, and OPL at P7. Protein assays were performed by WB with $50 \mu \mathrm{g}$ of protein for each sample and specific primary antibodies against Opn $4 \mathrm{x}$ and $\alpha$-tubulin (tubulin). For Opn $4 \mathrm{x}$, immunoblots showed bands of $\sim 55$ to 60 and $65 \mathrm{kDa}$. Results shown are representative of three blots from independent experiments.

Invitrogen). RNA integrity was checked in $1.5 \%$ agarose gel and quantified by UV spectrophotometry (Gene Quant spectrophotometer; GE Healthcare, Madrid, Spain). Finally, 1 to $2 \mu \mathrm{g}$ of total RNA was treated with DNase (Promega, Madrid, Spain) to eliminate contaminating genomic DNA. cDNA was synthesized with M-MLV (Promega), using oligo(dT).

Oligonucleotides were designed on computer (Vector NTI Advance 10 ; Invitrogen) to generate 100 - to 400 -bp products. The oligonucleotide sequences used for RT-PCR from the Gallus gallus sequences were as follows:

GAPDH forward: 5'AGG CGA GAT GGT GAA AGT CG 3', reverse: 5' TCT GCC CAT TTG ATG TTG CT 3'; Pax6 forward: 5' GGG AGT AGA GGC ACG CAG ATG T 3', reverse: 5' GGA GTC GCT ACT CTC GGC TTA CTA 3'; Brn3 forward: 5' CCA TCC TGC ACG AGC CCA AGT A 3', reverse: 5' GCC CCG TAG CAA GGT CTC ATC AA 3'; CRX forward: 5' GCA CAG CCC AGA GCA TGA TGT CC 3', reverse: 5' CTC CAG GAT GTC CAA CTG CGC C 3'; Opn $4 \mathrm{~m}$ forward: 5' TCT CGC CGT AGA ACA TCC 3', reverse: 5' GAA GTG TTT CAG AGC AAG GTA GGA 3'; Opn4x forward: 5' TGC TTT GTC AAC AGC TTG CAC AGA G 3', 
reverse: 5' CAG CAA TAA TCT GTA TGG TGC GCT TC 3'; Gq forward 5' TCA AAA CAT CTT CAC TGC CAT G 3', reverse: 5' TCC ACG TCG CTG AGA TAG TAT T $3^{\prime} ; \alpha$-transducin forward: $5^{\prime}$ AAG GAC CTC AAC TTC AGG ATG T 3', reverse: 5' CAG TCC TTG AGG TTC TCC TTG 3'; red opsin forward: 5'CAC GAA GAG GAG GAC ACC AC 3', reverse: 5' CGA GAT CTG GTT GAT GAC GCT 3'; and rhodopsin forward: 5'AGG GCC AAG ACT TCT ACG TGC 3', reverse: 5'ATG ATC CAG GAG AAC GCG ACC 3

\section{Statistics}

Statistical analyses involved one- or two-way analysis of variance (ANOVA) with Duncan post hoc tests or Student's $t$-tests, when appropriate (significance at $P<0.05$ ).

\section{Results}

\section{Onset of Nonvisual Gene Expression in the Embryonic Retina and RGCs}

The presence of specific markers for prospective RGCs, Pax6 and Brn3, was detected as early as E4, whereas the PRCspecific marker $C R X$ became detectable by E7 (Fig. 1A, left). When we examined the components of the nonvisual phototransduction cascades, $\mathrm{G}$ protein $\mathrm{q}(G q)$ mRNA together with trace $O p n 4 m$ transcripts were observed at E4, whereas $O p n 4 m$ expression became clearly detectable by E5 and remained robust throughout the different stages examined through E18. By contrast, Opn $4 x$ appeared several days later in the whole embryonic retina, exhibiting trace levels by E7 to E8 and robust levels by E10 to E12. The onset of expression of components of the visual photocascade was substantially delayed, as observed for $\mathrm{G}$ protein $\alpha$-transducin ( $\alpha$-trans) and red cone opsin by E8 to E10 and rhodopsin by E12. When the presence of RNAs was investigated in immunopurified RGC primary cultures, and compared with RNAs at E18 from the whole retina, we observed detectable mRNA for Opn $4 m$, Opn $4 x$, and $G q$ in the primary cultures, but not for transcripts of red cone opsin, rhodopsin, or $\alpha$-trans (Fig. 1A, right).

\section{Onset of Nonvisual Opsins in the Developing Retina and RGCs}

We examined both Opn $4 \mathrm{x}$ and Opn $4 \mathrm{~m}$ in embryonic and posthatching retina and RGC cultures. Western blot analysis revealed positive immunoreactivity for Opn $4 \mathrm{~m}$ at all embryonic stages examined. There were three main bands of $\sim 48$, 62 , and $67 \mathrm{kDa}$. The 48 - and $67-\mathrm{kDa}$ bands were prominent at all times examined, whereas the 62 -kDa band decreased markedly at P7. Binding was also found in RGC cultures, showing the same three bands seen in whole retina, but with more intense staining at 48 and $67 \mathrm{kDa}$. There was no clear binding in $\mathrm{ON}$ preparations from $\mathrm{P} 7$ chicks.

Immunoreactivity associated with Opn $4 \mathrm{x}$ was observed in the whole retina from E8 onward, exhibiting three bands of $\sim 56,65$, and $70 \mathrm{kDa}$ (Fig. 1C). The two Opn4x-immunoreactive bands with higher MW were strongly stained at E8 to E11 and decreased by E15; the $56-\mathrm{kDa}$ band appeared at E11, increased by E15, and remained elevated at later stages, with an additional band appearing at $\sim 62 \mathrm{kDa}$ around the time of hatching. The 56-kDa band was strongly stained in ON samples at P7. Positive binding was also observed in RGC cultures, in which only the two bands of higher MW were clearly observed.

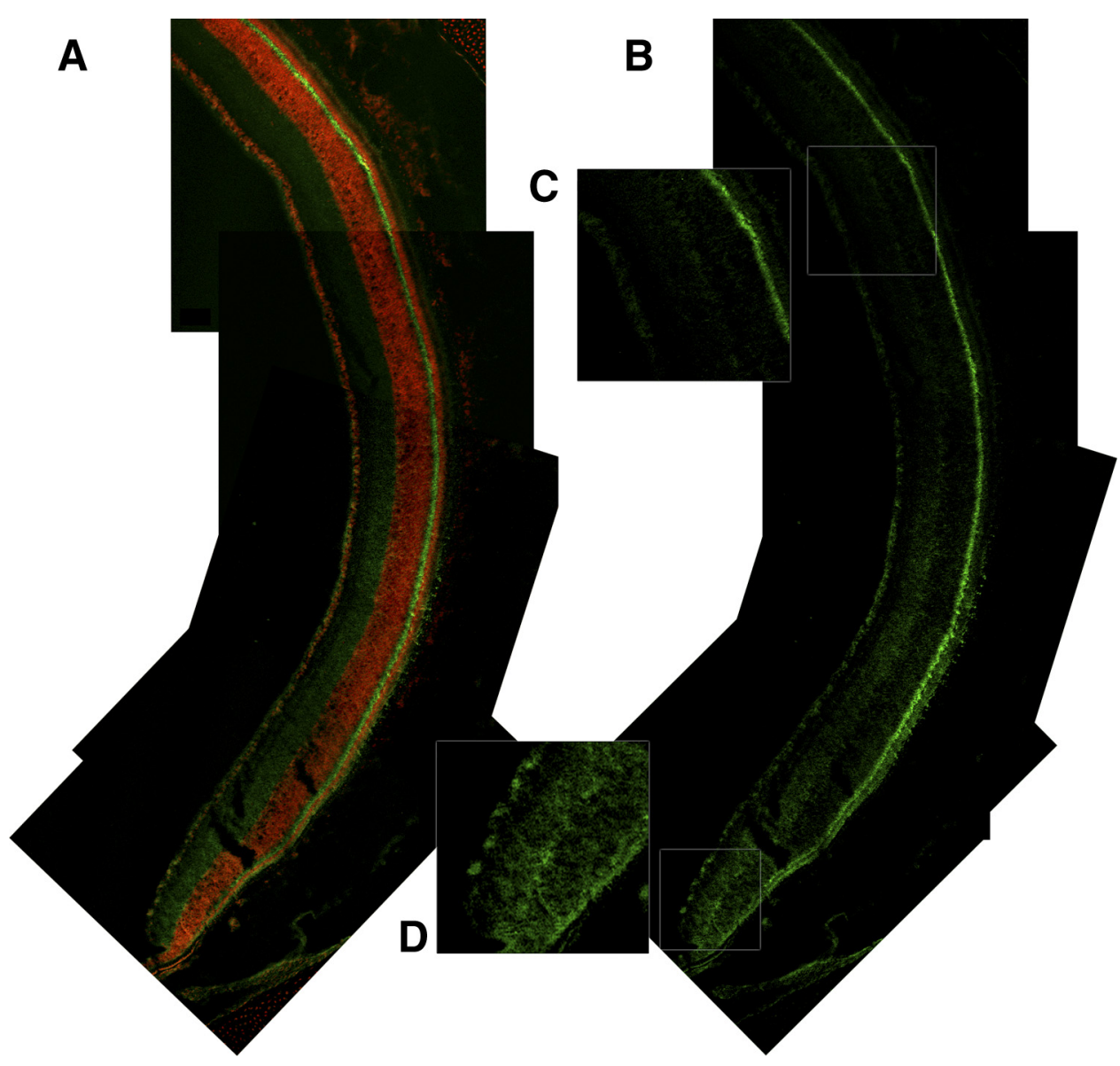

FIGURE 4. Opn4x immunoreactivity in mature chicken retina. Serial retinal sections from marginal to central zones of a retina at $\mathrm{P} 7$ were stained for propidium iodide (red) and Opn4x (green) (A) or Opn $4 x$ only $(\mathbf{B}, \mathbf{C})$ with the specific primary antibody and visualized by confocal microscopy at $40 \times(\mathbf{A}, \mathbf{B})$ or higher magnification (C, D). Opn $4 x$ immunoreactivity was present throughout the retina, including the OPL and GCL. Discrete areas of central and peripheral retina are highlighted in the insets in (C) and (D), respectively. Scale bar, $40 \mu \mathrm{m}$. 


\section{Expression of Opn 4 Proteins in the Developing Chicken Retina and RGC Cultures}

We investigated the presence and localization of both Opn 4 proteins in sections of developing retina and RGC cultures. Opn $4 \mathrm{~m}$ immunostaining was mostly restricted to cell soma membranes within the GCL in all ages examined (Fig. 2). In contrast, Opn $4 \mathrm{x}$ was mainly located in axonal fibers of the forming GCL at E8 to E11 (Figs. 3A, 3B), with strong immunoreactivity appearing in the OPL by $\mathrm{E} 15$ and later (Figs. 3C, 3E). Immunoblotting for Opn $4 \mathrm{x}$ in $\mathrm{P} 7$ samples clearly showed the $56-\mathrm{kDa}$ band in whole retinal and ON samples, whereas an additional band of $\sim 65 \mathrm{kDa}$ was observed in enriched OPL preparations (Fig. 3F). Moreover, in serial sections of a mature WT chicken retina from the marginal to the central zone, Opn $4 \mathrm{x}$ was clearly visualized throughout the OPL as well as in clusters of cells in the GCL, mainly in the periphery (Fig. 4). In addition, immunostaining of Opn $4 \mathrm{~m}$ and Opn $4 \mathrm{x}$ proteins was clearly visualized in RGC cultures (Supplementary Figs. S1, S2, http://www.iovs.org/lookup/suppl/doi:10.1167/iovs.11-75301/-/ DCSupplemental) visible as clusters of Opn $4(+)$ cells (Supplementary Fig. S1). Quantification of numbers of immunostained cells indicated that RGC cultures contained $10.7 \% \pm 3.0 \%$ Opn $4 x(+)$ cells, and $23.2 \% \pm 2.2 \%$ Opn $4 \mathrm{~m}(+)$ cells. Supplementary Figures S2G-I (http://www.iovs.org/lookup/suppl/ doi:10.1167/iovs.11-75301/-/DCSupplemental) show intense Opn 4x labeling in neurites of an individual RGC kept in culture for 5 days.

In addition, compared with Opn $4 x$ immunoreactivity in normal chickens (Fig. 5A), retinal sections of retinal degeneration GUCY1* chickens showed markedly stronger immunostaining in the different layers (Fig. 5B) and was especially intense in the GCL with bundles of strongly labeled processes. Discrete staining of axonal elements was observed in sections of normal ON (data not shown) and more strongly in GUCY1* ON (Fig. 5C; Supplementary Fig. S3, http://www.iovs.org/lookup/suppl/doi:10.1167/iovs.11-75301/-/DCSupplemental).

\section{Cell Layer Characterization of Opn $4 x$ Expression in the Developing Chicken Retina}

To identify cells expressing Opn $4 \mathrm{x}$ at E15 and later in the OPL, we examined the co-localization of this photopigment with different markers for cells in the INL (horizontal cells, HCs; bipolar cells, BCs) and ONL (rod and cone and PRCs) (Figs. 6-8). No co-localization was observed by confocal microscopy between Opn $4 x$ immunoreactivity and PRC staining with anti-rhodopsin (restricted to outer segments) and anticone transducin (Fig. 6) or with a marker for "ON" type BCs (115a10) within the INL (Fig. 7). By contrast, positive colocalization was visualized in the OPL and adjacent INL between Opn 4x and Prox1, an HC nuclear marker in both WT (Figs. 8A-C) and GUCY1* chickens (Fig. 8D). Opn4x immunofluorescence clearly labeled the cell soma and neurites of typical HCs (Figs. 8B, 8C). At longer incubation times, immunofluorescence could be clearly visualized in distinct inner plexiform layer (IPL) sublaminas, which did not correspond with "ON" BC axonal arborization (Fig. 7). We also observed that Opn $4 \mathrm{x}$ immunoreactivity in the $\mathrm{HC}$ juxtaposed bipolar terminals in the OPL.

\section{Discussion}

Opn 4 was initially discovered in Xenopus and later found in the brain, iris, and retinal cells from most vertebrates tested. ${ }^{2,6,19,28-32}$ In mammals Opn 4 is only expressed in a small RGC subset ${ }^{2,6,29,32,33}$ and was identified as the photopigment conferring intrinsic photosensitivity to these cells. ${ }^{1,3,9,14}$
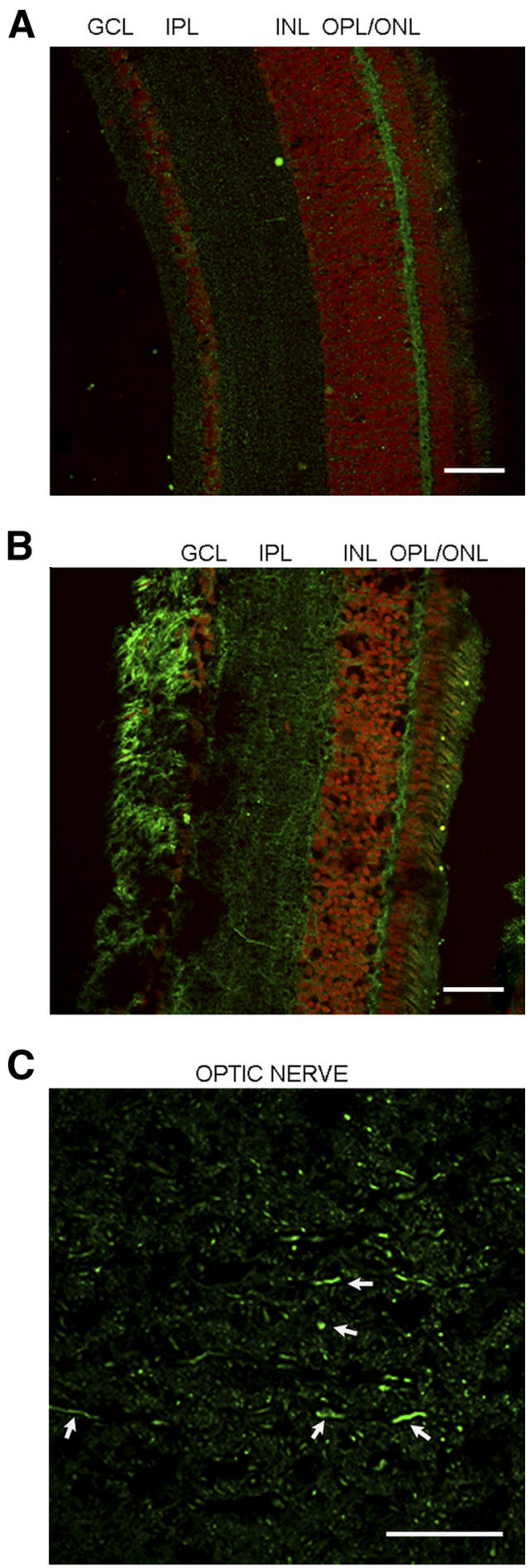

FigURE 5. Opn $4 \mathrm{x}$ immunoreactivity in sections of a wild-type retina (A), GUCY1* chicken retina (B), and ON (C). Sections were immunolabeled for Opn 4x (green) and propidium iodide (red) and visualized by confocal microscopy at $40 \times$ magnification. Positive Opn $4 x$ immunoreactivity was visualized mainly in the OPL of wild-type chicks and intensely in different layers of the GUCY1* retina and ON. (C, white arrows) Intense Opn $4 \mathrm{x}$ immunolabeling in axonal fibers. Scale bar, $40 \mu \mathrm{m}$.

Mammals uniquely express Opn $4 \mathrm{~m}$, whereas nonmammalian vertebrates express both genes. ${ }^{11}$ In mammals, melanopsinexpressing RGCs project to brain areas involved in diverse visual and NIF tasks regulated by light. ${ }^{34-36}$ The function of 

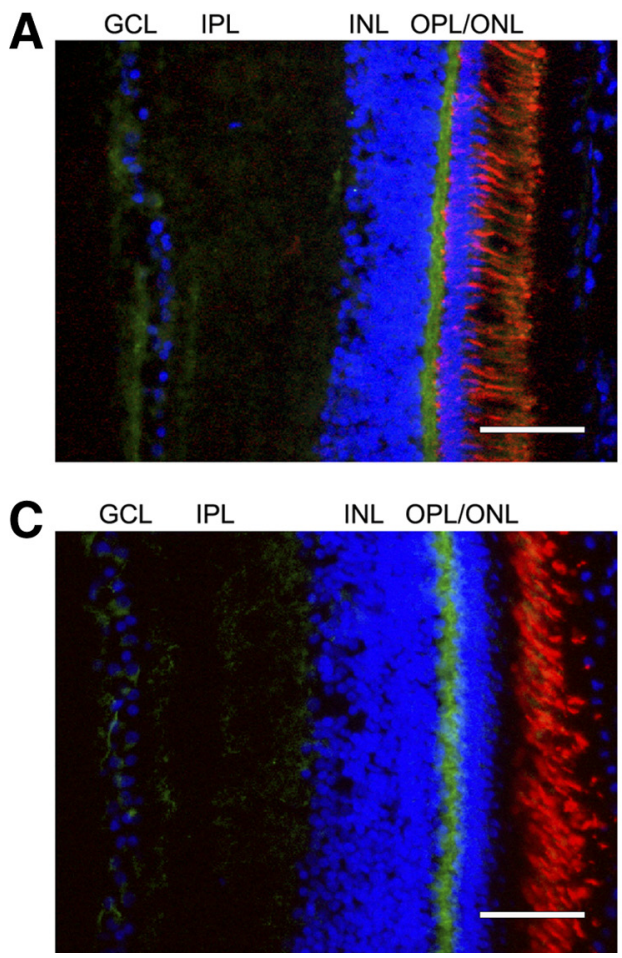

B

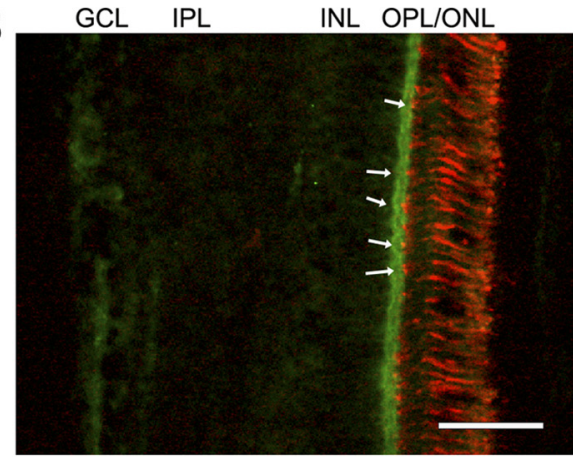

D

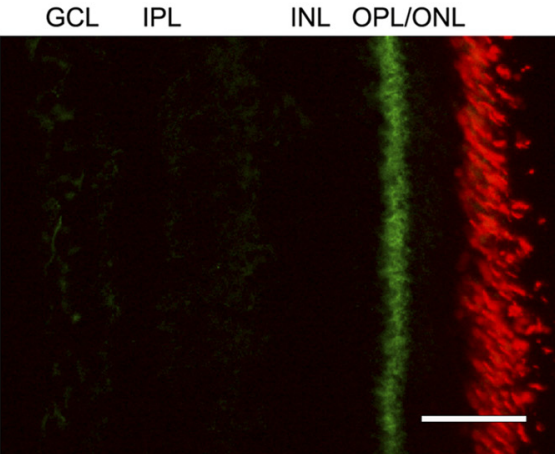

FIGURE 6. Characterization of immunoreactivity for Opn $4 \mathrm{x}$ and INL and ONL components with specific markers of the chicken retina at P7. Consecutive retinal sections were immunolabeled for Opn4x (green; A-D) and nuclear staining with DAPI (blue; A, C), together with GTa1- $\alpha$ cone transducin (red; $\mathbf{A}, \mathbf{B})$ and rhodopsin (rho4d2, red; C, D), and visualized by confocal microscopy with specific primary antibodies at $20 \times$ magnification. Merging of immunofluorescence signals is shown in (B) and (D) with no DAPI staining; no co-localization was found between Opn $4 \mathrm{x}$ and the two photoreceptor antibody markers as marked by white arrows in B. Scale bar, $50 \mu \mathrm{m}$.
Opn4x is not known but is thought to be similar. Opn $4 \mathrm{x}$ is lacking in different eutherian mammals, ${ }^{11,35}$ likely coinciding with a nocturnal period of mammalian evolution ${ }^{37}$ and a gen- eral reduction in photosensitivity. More extensive photodetection systems have been retained in birds and other vertebrates during evolution, involving the pineal organ and encephalic

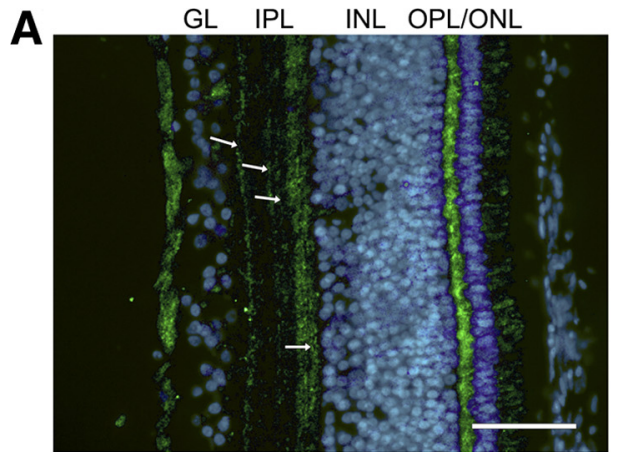

B

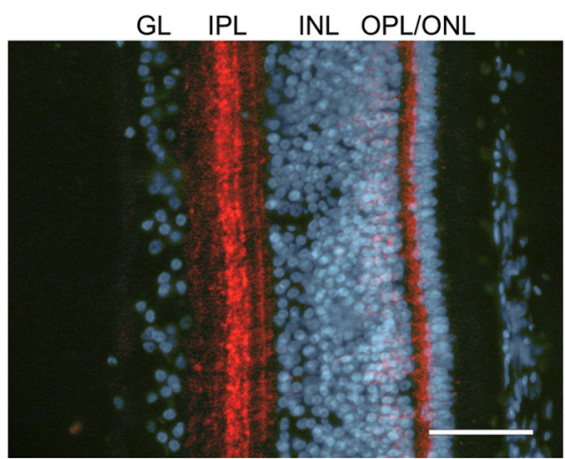

C

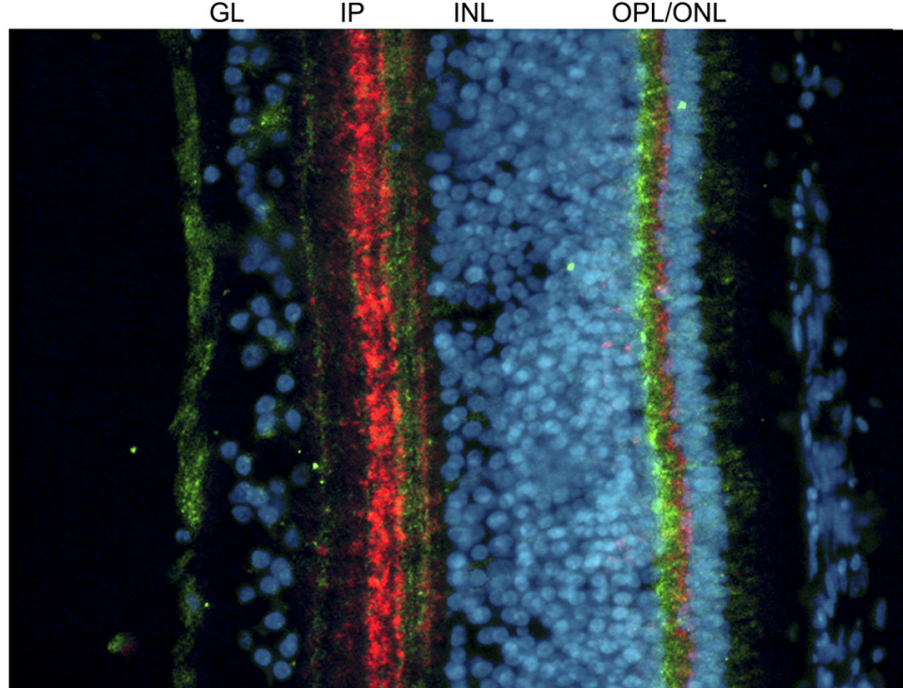

FIGURE 7. Characterization of immunoreactivity for Opn $4 \mathrm{x}$ and "ON" bipolar cells in the chicken retina at P7. Retinal sections were immunolabeled for Opn 4 x (green; $\mathbf{A}, \mathbf{C})$ and an "ON" bipolar cell marker (115A10) (red; B, C) and nuclear staining by DAPI (blue; A-C). Marked Opn4x staining can be seen in HCs and axons in the nerve fiber layer, as well as in discrete sublamina within the IPL (arrows, A). "ON" bipolar cell axons also ramified in the IPL, but merged images of the double-stained sections show no overlap between the two plexi (C). Furthermore, the close nonoverlapping apposition of Opn $4 x$ in $\mathrm{HC}$ dendrites in the lower OPL and 115A10 staining of "ON" bipolar cell dendrites in the upper OPL can be clearly seen (C). Faint labeling of photoreceptor outer segments is due to autofluorescence. Scale bar, $50 \mu \mathrm{m}$. 
A

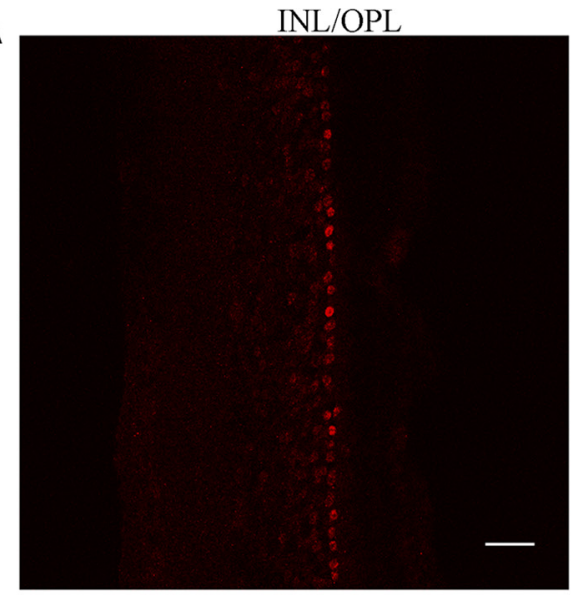

C

Figure 8. Co-localization of Opn $4 x$ immunoreactivity with Prox1, an HC marker in the retina of WT and GUCY1* chickens. Immunohistochemistry for Prox1 (red; A, C, D) and Opn $4 x$ (green; B-D) in the chicken retina at $\mathrm{P} 7$. Retinal sections were immunolabeled for Prox1 (A) or Opn 4x (B), or sequentially stained for both antibodies and merged (WT, C; GUCY1*, D). Arrows: (B) A typical axonless candelabrum $\mathrm{HC}$ stained for Opn 4x;in; (C) and (D) and inset in (D) Opn $4 x$ and Prox 1 co-localization. Scale bar, $20 \mu \mathrm{m}$.
B

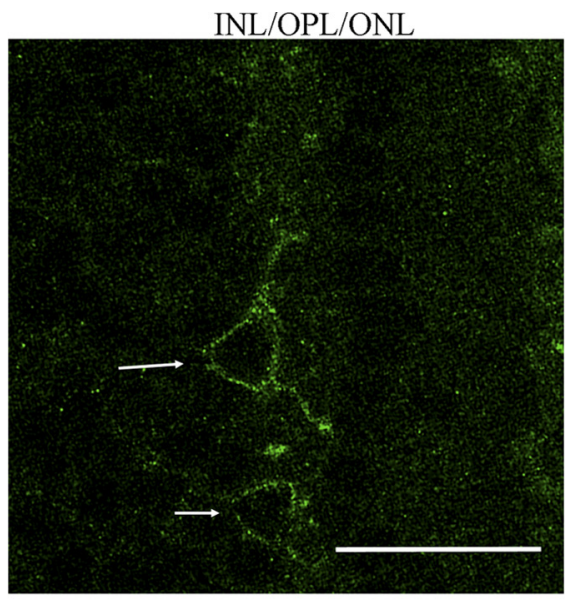

D

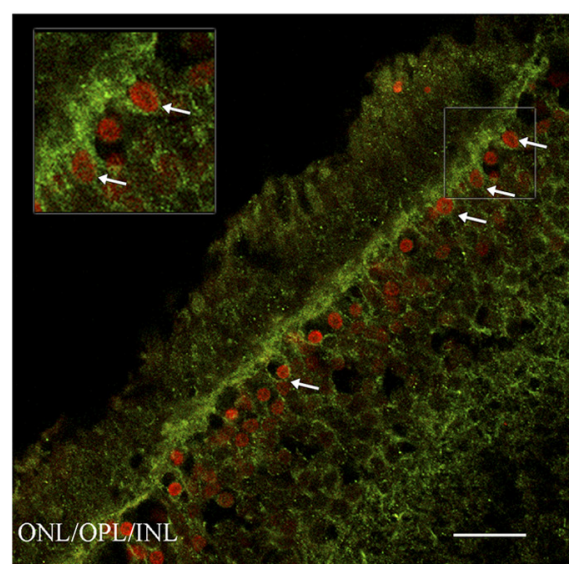

photoreceptors; within the retina, this would include noncanonical PRCs. ${ }^{38}$ These nonclassic photoreceptors can be active in measuring day length and implicated in diverse light-regulated processes (i.e., seasonal reproduction and migration).

Initial expression of both Opn 4 orthologues is confined to the emerging RGCs (Fig. 1). The expression of each orthologue correlates with a distinct phase of RGC development: onset of Opn $4 m$ and $G q$ mRNA coincides with RGC birth around $\mathrm{E} 4,{ }^{12,39}$ and early $\mathrm{Opn} 4 \mathrm{~m}$ appearance has been reported in mammals. ${ }^{40-44}$ The onset of Opn $4 \mathrm{x}$ expression is markedly later, commencing around E8 and coinciding with the time at which retinotectal projections are forming and arriving at laminas of the optic tectum by E6 to E8. ${ }^{45-50}$ Strong Opn $4 x$ expression is observed in axonal fibers of RGCs and persists in the ON throughout maturation. The spatial distribution of Opn $4 \mathrm{~m}$ protein differed greatly from that of Opn $4 \mathrm{x}$ at later times in retinal development. Whereas Opn $4 \mathrm{~m}$ remained expressed exclusively in an RGC subpopulation at all ages examined, in addition to RGC localization, Opn $4 \mathrm{x}$ was switched on in HCs by E15. Previous in situ hybridization studies showed quite widespread distribution for both orthologues, with detectable mRNA in all cellular layers. ${ }^{11,20}$ Antibody staining patterns in the present study were more restricted, possibly because protein levels in many cells are below detection limits. Transgenic mice expressing reporter genes under Opn 4 promoter control revealed far more positive cells than detected by IHC. ${ }^{51}$ Indeed the retinal pattern we see for Opn $4 \mathrm{~m}$ protein distribution is identical with that of mammals, restricted to the RGC layer at all ages examined. On the other hand, previous in situ hybridization studies more closely resembled the antiOpn $4 \mathrm{x}$ antibody data. ${ }^{17}$ Opn $4 x$ mRNA was shown to be rhythmically expressed in the mature chicken retina, ${ }^{18,19}$ and was particularly expressed in the outer INL. ${ }^{19}$ Using the same antibody, Opn $4 x$ staining was previously detected in RGCs and general neurons in the INL, including $\mathrm{HC}$, although no cell-type identification was performed. ${ }^{21,52}$ We were unable to detect any immunostaining in rod or cone photoreceptors, or bipolar cells ("ON" subtype). It should be stressed that Opn $4 x$ continued to be expressed by an RGC subpopulation, as witnessed from the immunostaining of discrete axons in P7 ON. The target region(s) innervated by these Opn $4 x$-positive RGCs is currently unknown.

Immunoblotting for both Opn 4 proteins revealed the presence of several main bands $(\sim 48-67 \mathrm{kDa}$ for Opn $4 \mathrm{~m}$, and 56-70 kDa for Opn $4 x$ ). The in silico analysis for both Opn4 proteins from their mRNA sequences identify long (L), short (S), and super short (SS) isoforms of $58.5,47.7$, and $35.9 \mathrm{kDa}$, respectively, for Opn $4 \mathrm{~m}$, and a long (L) and a short (S) isoform of 60.3 and $47.6 \mathrm{kDa}$, respectively, for Opn $4 \mathrm{x} .{ }^{16}$ The persistence of the three Opn $4 \mathrm{~m}$-immunoreactive bands at all embryonic ages and in cultured RGCs, and their relative absence from ON, indicates the these forms are all confined to RGC and dendrites. They may correspond to the three alternatively spliced Opn $4-2$ isoforms cloned. ${ }^{16}$ Alternatively, the uppermost band may result from posttranslational modifications such as glycosylation. ${ }^{26}$ Opn $4 x$ immunoblots showed age-related changes in band profiles, with a transition from an early pattern (E8-E11) dominated by high molecular mass bands toward one with a mainly low molecular mass isoform (E15 onward) enriched in RGC axons. This low-mass isoform may correspond to the short Opn $4 \mathrm{x}$ isoform Opn $41 \mathrm{~S}$ previously identified $^{16}$ and suggests that it serves specific roles in retinal photosensitivity. The robust expression in $\mathrm{HC}$ is seen as a 


\section{Non-visual onset}

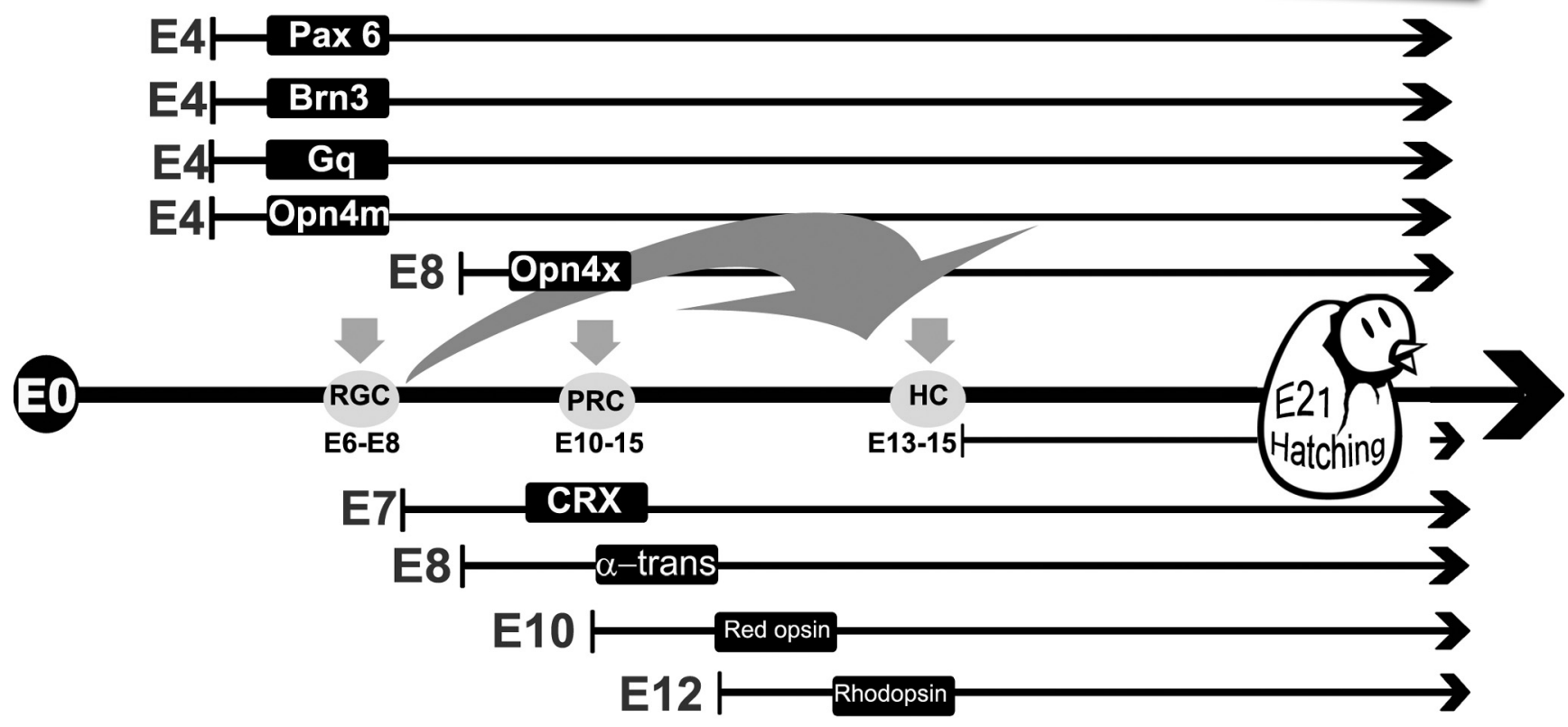

Visual onset

SCHEME 1. Time line for the onset of expression of opsins and photocascade elements in the visual and nonvisual systems in the developing chicken retina. Embryonic retinas expressed specification genes for prospective RGCs, such as Pax6 and Brn3, and components of the nonvisual phototransduction cascade like Opn $4 m$ and Gq mRNAs at very early stages (E4-E5). On the contrary, the expression of PRC markers (CRX, red-opsin, rhodopsin, and $\alpha$-transducin) was observed from E7 to E12. Opn $4 \mathrm{~m}$ protein was visualized in the whole retina as early as E4 and remained elevated from E6 to postnatal days, mainly localized in the GCL, whereas Opn4x was first detected at E8 in axonal fibers of the GCL. By E15 and onward, it was highly expressed in the OPL, mostly in HCs, but in a few RGCs. The ON RGCs were mostly mature by E8, the PRCs after E10. HCs differentiated and migrated to the INL by E13 to E15.

higher mass form, possibly corresponding to Opn $41 \mathrm{~L},{ }^{16}$ and again indicates a selective function in inner retinal processing.

After cell fate determination, HC precursors migrate, differentiate, and acquire the appropriate morphology for their function in visual perception. ${ }^{53}$ In the chicken retina, three different cell types (H1, H2, and $\mathrm{H} 3)$ were characterized by a distinct morphology ${ }^{54}$ : $\mathrm{H} 1$ is an axon-bearing HC, while H2 "stellate" and $\mathrm{H} 3$ "candelabrum-shaped" are axonless HCs. Concomitantly with HC birth and migration between E10 and E15 $5^{55,56}$ Opn $4 x(+)$ immunoreactivity appeared in the cell somas of Prox1 ( + ) HC and displayed prominent labeling of the lower OPL. Morphologically, some of these Opn $4 x$ cells are candelabrum axonless HCs, which mainly connect to cone pedicles. ${ }^{53,55}$ Close imbrications of cone pedicles and Opn $4 x-$ immunopositive HC processes were seen in our IHC studies. Remarkably, cone HCs in fish are directly light sensitive and express Opn $4 \mathrm{~m} .{ }^{13}$ In the chicken, Opn $4 \mathrm{x}$ could play a role in receptive field construction (cones, horizontal cells, bipolar cells, and RGCs). It is intriguing to speculate how Opn $4 x$ may modify $\mathrm{HC}$ responses to light, since they are normally hyperpolarized in response to rod and cone input after light onset, whereas activation of Opn $4 x$ would blunt such activity through an opposing depolarization. Such influences would be further influenced by two additional factors: first, circadian fluctuations in Opn $4 \mathrm{x}$ levels, ${ }^{19}$ with the highest expression in outer INL occurring at ZT4; second, direct recording of Opn4X- dependent light-induced currents indicates less reproducible and lower amplitude responses than Opn $4 \mathrm{~m} .{ }^{11}$ Finally, shared Opn $4 x$ expression by HC and RGCs in birds suggests that they are ancestrally related cells. ${ }^{12}$

Opn 4 has been phylogenetically related to invertebrate rhodopsin, which couples to invertebrate Gq protein, ${ }^{57-60}$ and full-length Amphioxus melanopsin activates Gq with an efficiency similar to that of Gq-coupled visual pigments. ${ }^{61}$ On the contrary, expression of components of the visual phototransduction cascade was noticeably delayed: $\alpha$-transducin and red cone opsin were first detected at E8 to E10, and rhodopsin at E12, after the appearance of the PRC marker CRX around E6 and E7. This agrees with the sequence of timing for the onset of PRC markers and visual photopigments reported previously ${ }^{62-64}$; red and green cone opsins were detected first at E14 and rhodopsin around E15. The developmental onset of both visual and nonvisual photocascade elements is summarized in Scheme 1. Primary cultures of E8 RGCs also expressed noncanonical photocascade elements such as the $G q$ and the two Opn 4 genes, but not $\mathrm{G} \alpha$-transducin or red cone opsin, both markers of PRCs (Fig. 1; Supplementary Figs. S1, S2, http://www.iovs.org/lookup/suppl/ doi:10.1167/iovs.11-75301/-/DCSupplemental). Strikingly, RGC cultures are intrinsically photosensitive and respond to light by triggering an invertebrate-like phototransduction cascade. ${ }^{10,15}$ In addition, GUCY1* chickens which lack functional classic photoreceptors respond to light that mediates photic entrainment of 
feeding rhythms and pupil reflexes and express both $O p n 4 x$ and Opn $4 m$ transcripts in their retinas. ${ }^{5}$ Opn $4 \mathrm{x}$ immunoreactivity was highly expressed in GUCY1* retina, particularly in the GCL, INL, and OPL and with intense staining in RGC axons (Fig. 5). Rodent models of photoreceptor degeneration show either suppression $^{65,66}$ or no effect ${ }^{67}$ on downstream Opn $4 \mathrm{~m}$ expression. In the present case, Opn $4 x$ over-expression may be a compensatory mechanism for the absence of classic rod and cone input.

\section{Conclusions}

Taking all this information together with findings in previous work, ${ }^{10,15,64}$ developing chicken retina exhibits early expression of components for the nonvisual phototransduction cascade. This early photosensitivity mediated by $O p n 4$ in ipRGCs may act as an immature form of vision, since these cells may also project to image-forming visual areas, ${ }^{2,51,68,69}$ supporting the idea that "second sight comes first." $17,70,71$ The appearance of Opn $4 x$ expression in HC by E15 strongly suggests the existence of a novel type of photosensitive retinal cell in birds, implicating novel connections between outer and inner retina and a higher degree of complexity in mechanisms of light detection, processing, and transmission to the brain.

\section{Acknowledgments}

The authors thank Cecilia Sampedro, Susana Deza, and Gabriela Schachner for excellent technical support; and Martin Zatz, Arjun Natesan, Ignacio Provencio, and Ana Maria Castrucci for the kind gift of the Opn $4 x$ antibody.

\section{References}

1. Berson DM, Dunn FA, Takao M. Phototransduction by retinal ganglion cells that set the circadian clock. Science. 2002;295: $1070-1073$

2. Hattar S, Liao HW, Takao M, Berson DM, Yau KW. Melanopsincontaining retinal ganglion cells: architecture, projections, and intrinsic photosensitivity. Science. 2002;295:1065-1070.

3. Lucas RJ, Hattar S, Takao M, Berson DM, Foster RG, Yau KW Diminished pupillary light reflex at high irradiances in melanopsinknockout mice. Science. 2003;299:245-247.

4. Panda S, Sato TK, Castrucci AM, et al. Melanopsin (Opn4) requirement for normal light-induced circadian phase shifting. Science. 2002;298:2213-2216.

5. Valdez DJ, Nieto PS, Garbarino-Pico E, et al. A nonmammalian vertebrate model of blindness reveals functional photoreceptors in the inner retina. FASEB J. 2009;23:1186-1195.

6. Provencio I, Rodriguez IR, Jiang G, Hayes WP, Moreira EF, Rollag MD. A novel human opsin in the inner retina. J Neurosci. 2000 20:600-605.

7. Melyan Z, Tarttelin EE, Bellingham J, Lucas RJ, Hankins MW Addition of human melanopsin renders mammalian cells photoresponsive. Nature. 2005;433:741-745.

8. Panda S, Nayak SK, Campo B, Walker JR, Hogenesch JB, Jegla T Illumination of the melanopsin signaling pathway. Science. 2005 307:600-604

9. Qiu X, Kumbalasiri T, Carlson SM, et al. Induction of photosensitivity by heterologous expression of melanopsin. Nature. 2005; 433:745-749.

10. Contin MA, Verra DM, Guido ME. An invertebrate-like phototransduction cascade mediates light detection in the chicken retinal ganglion cells. FASEB J. 2006;20:2648-2650.

11. Bellingham J, Chaurasia SS, Melyan Z, et al. Evolution of melanopsin photoreceptors: discovery and characterization of a new melanopsin in nonmammalian vertebrates. PLOS Biol. 2006;4:e254.

12. Arendt D. Evolution of eyes and photoreceptor cell types. Int J Dev Biol. 2003;47:563-571.

13. Cheng $\mathrm{N}$, Tsunenari $\mathrm{T}$, Yau $\mathrm{KW}$. Intrinsic light response of retinal horizontal cells of teleosts. Nature. 2009;460:899-903.
14. Isoldi MC, Rollag MD, Castrucci AM, Provencio I. Rhabdomeric phototransduction initiated by the vertebrate photopigment melanopsin. Proc Natl Acad Sci U S A. 2005;102:1217-1221.

15. Contin MA, Verra DM, Salvador G, Ilincheta M, Giusto NM, Guido ME. Light-activation of the phosphoinositide cycle in intrinsically photosensitive chicken retinal ganglion cells. Invest Ophthalmol Vis Sci. 2010;51(11):5491-5558.

16. Torii M, Kojima D, Okano T, et al. Two isoforms of chicken melanopsins show blue light sensitivity. FEBS Lett. 2007;581: $5327-5331$

17. Tomonari S, Takagi A, Akamatsu S, Noji S, Ohuchi H. A noncanonical photopigment, melanopsin, is expressed in the differentiating ganglion, horizontal, and bipolar cells of the chicken retina. Dev Dyn. 2005;234:783-790.

18. Bailey MJ, Cassone VM. Melanopsin expression in the chick retina and pineal gland. Brain Res Mol Brain Res. 2005;134:345-348.

19. Chaurasia SS, Rollag MD, Jiang G, et al. Molecular cloning, localization and circadian expression of chicken melanopsin (Opn4): differential regulation of expression in pineal and retinal cell types. J Neurochem. 2005;92:158-170.

20. Tomonari S, Takagi A, Noji S, Ohuchi H. Expression pattern of the melanopsin-like (cOpn4m) and VA opsin-like genes in the developing chicken retina and neural tissues. Gene Expr Patterns. 2007;7:746-753.

21. Lima LH, M. SA, Isoldi MC, A. VM, Castrucci AM. Melanopsin in chicken melanocytes and retina. Biol Rhythm Res. 2006;37:393404 .

22. Garbarino-Pico E, Carpentieri AR, Contin MA, et al. Retinal ganglion cells are autonomous circadian oscillators synthesizing $\mathrm{N}$ acetylserotonin during the day. J Biol Chem. 2004;279:5117251181

23. Guido, ME, Bussolino DF, de Arriba Zerpa G, et al. A simple method to obtain retinal cell preparations highly enriched in specific cell types: suitability for lipid metabolism studies. Brain Res Prot. 1999;4:147-155.

24. Hicks D, Molday RS. Differential immunogold-dextran labeling of bovine and frog rod and cone cells using monoclonal antibodies against bovine rhodopsin. Exp Eye Res. 1986;42:55-71.

25. Euler T, Wassle H. Immunocytochemical identification of cone bipolar cells in the rat retina. J Comp Neurol. 1995;361:461-478.

26. Fahrenkrug J, Falktoft B, Georg B, Rask L. N-linked deglycosylated melanopsin retains its responsiveness to light. Biochemistry. 2009; 48:5142-5148

27. Chomczynski P, Sacchi N. Single-step method of RNA isolation by acid guanidinium thiocyanate-phenol-chloroform extraction. Anal Biochem. 1987;162:156-159.

28. Drivenes O, Soviknes AM, Ebbesson LO, Fjose A, Seo HC, Helvik JV. Isolation and characterization of two teleost melanopsin genes and their differential expression within the inner retina and brain. J Comp Neurol. 2003;456:84-93.

29. Provencio I, Rollag MD, Castrucci AM. Photoreceptive net in the mammalian retina: this mesh of cells may explain how some blind mice can still tell day from night. Nature. 2002;415:493.

30. Bellingham J, Whitmore D, Philp AR, Wells DJ, Foster RG. Zebrafish melanopsin: isolation, tissue localisation and phylogenetic position. Brain Res Mol Brain Res. 2002;107:128-136.

31. Gooley JJ, Lu J, Chou TC, Scammell TE, Saper CB. Melanopsin in cells of origin of the retinohypothalamic tract. Nat Neurosci. 2001;4:1165.

32. Jenkins A, Munoz M, Tarttelin EE, Bellingham J, Foster RG, Hankins MW. VA opsin, melanopsin, and an inherent light response within retinal interneurons. Curr Biol. 2003;13:1269-1278.

33. Dkhissi-Benyahya O, Rieux C, Hut RA, Cooper HM. Immunohistochemical evidence of a melanopsin cone in human retina. Invest Ophthalmol Vis Sci. 2006;47:1636-1641.

34. Berson DM. Phototransduction in ganglion-cell photoreceptors. Pflugers Arch. 2007;454:849-855.

35. Peirson SN, Halford S, Foster RG. The evolution of irradiance detection: melanopsin and the non-visual opsins. Philos Trans $R$ Soc Lond B Biol Sci. 2009;364:2849-2865.

36. Guido ME, Garbarino-Pico E, Contin MA, et al. Inner retinal circadian clocks and non-visual photoreceptors: novel players in the circadian system. Prog Neurobiol. 2010;92(4):484-504. 
37. Heesy CP, Hall MI. The nocturnal bottleneck and the evolution of mammalian vision. Brain Behav Evol. 2010;75:195-203.

38. Dunlap JC, Loros JJ, DeCoursey PJ. Circadian rhythms and photoperiodism. Chronobiology: Biological Timekeeping. Sunderland, MA: Sinauer Associates; 2004:127-131.

39. Mey J, Thanos S. Development of the visual system of the chick. I Cell differentiation and histogenesis. Brain Res Brain Res Rev. 2000;32:343-379.

40. Tarttelin EE, Bellingham J, Hankins MW, Foster RG, Lucas RJ. Neuropsin (Opn5): a novel opsin identified in mammalian neural tissue. FEBS Lett. 2003;554:410 - 416.

41. Fahrenkrug J, Nielsen HS, Hannibal J. Expression of melanopsin during development of the rat retina. Neuroreport. 2004;15:781784 .

42. Tu DC, Zhang D, Demas J, et al. Physiologic diversity and development of intrinsically photosensitive retinal ganglion cells. Neuron. 2005;48:987-999.

43. Schmidt TM, Taniguchi K, Kofuji P. Intrinsic and extrinsic light responses in melanopsin-expressing ganglion cells during mouse development. J Neurophysiol. 2008;100:371-384.

44. Gonzalez-Menendez I, Contreras F, Cernuda-Cernuda R, Provencio I, Garcia-Fernandez JM. Postnatal development and functional adaptations of the melanopsin photoreceptive system in the albino mouse retina. Invest Ophthalmol Vis Sci. 2010;51:4840-4847.

45. Goldberg S. Studies on the mechanics of development of the visual pathways in the chick embryo. Dev Biol. 1974;36:19.

46. Crossland WJ, Cowan WM, Rogers LA. Studies on the develop ment of the chick optic tectum. IV. An autoradiographic study of the development of retino-tectal connections. Brain Res. 1975;91:1-23.

47. McLoon SC. Evidence for shifting connections during development of the chick retinotectal projection. J Neurosci. 1985;5: $2570-2580$

48. Thanos S, Bonhoeffer F. Investigations on the development and topographic order of retinotectal axons: anterograde and retrograde staining of axons and perikarya with rhodamine in vivo. $J$ Comp Neurol. 1983;219:420 - 430.

49. Thanos S, Bonhoeffer F. Axonal arborization in the developing chick retinotectal system. J Comp Neurol. 1987;261:155-164.

50. Fujiwara A, Ohozone Y, Naito J. The developmental study on lamination of the optic tectum in relation to the retinotectal projection in chicks and chick embryos. J Vet Medical Sci. 2000; 62:511-516.

51. Ecker JL, Dumitrescu ON, Wong KY, et al. Melanopsin-expressing retinal ganglion-cell photoreceptors: cellular diversity and role in pattern vision. Neuron. 2010;67:49-60.

52. de Lima LH, dos Santos KP, de Lauro Castrucci AM. Clock genes, melanopsins, melatonin, and dopamine key enzymes and their modulation by light and glutamate in chicken embryonic retinal cells. Chronobiol Int. 2011;28:89-100.

53. Poche RA, Reese BE. Retinal horizontal cells: challenging paradigms of neural development and cancer biology. Development 2009;136:2141-2151.

54. Genis-Galvez JM, Prada F, Armengol JA. Evidence of three types of horizontal cells in the chick retina. Jpn J Opbthalmol. 1979;23: $378-387$.
55. Araki M, Kimura H. GABA-like immunoreactivity in the developing chick retina: differentiation of GABAergic horizontal cell and its possible contacts with photoreceptors. J Neurocytol. 1991;20: 345-355.

56. Boije H, Edqvist $\mathrm{PH}$, Hallbook F. Horizontal cell progenitors arrest in G2-phase and undergo terminal mitosis on the vitreal side of the chick retina. Dev Biol. 2009;330:105-113.

57. Koyanagi M, Kubokawa K, Tsukamoto H, Shichida Y, Terakita A Cephalochordate melanopsin: evolutionary linkage between invertebrate visual cells and vertebrate photosensitive retinal ganglion cells. Curr Biol. 2005;15:1065-1069.

58. Terakita A, Tsukahara Y, Hariyama T, Seki T, Tashiro H. Lightinduced binding of proteins to rhabdomeric membranes in the retina of crayfish (Procambarus clarkii). Vision Res. 1993;33:24212426.

59. Lee YJ, Shah S, Suzuki E, Zars T, O'Day PM, Hyde DR. The Drosophila dgq gene encodes a $\mathrm{G}$ alpha protein that mediates phototransduction. Neuron. 1994;13:1143-1157.

60. Kikkawa S, Tominaga K, Nakagawa M, Iwasa T, Tsuda M. Simple purification and functional reconstitution of octopus photoreceptor Gq, which couples rhodopsin to phospholipase C. Biochemistry. 1996;35:15857-15864.

61. Terakita A, Tsukamoto H, Koyanagi M, Sugahara M, Yamashita T, Shichida Y. Expression and comparative characterization of Gqcoupled invertebrate visual pigments and melanopsin. J Neurochem. 2008;105:883-890.

62. Bradford RL, Wang C, Zack DJ, Adler R. Roles of cell-intrinsic and microenvironmental factors in photoreceptor cell differentiation. Dev Biol. 2005;286:31- 45.

63. Bruhn SL, Cepko CL. Development of the pattern of photoreceptors in the chick retina. J Neurosci. 1996;16:1430-1439.

64. Cailleau V, Bernard M, Morin F, Guerlotte J, Voisin P. Differential regulation of melatonin synthesis genes and phototransduction genes in embryonic chicken retina and cultured retinal precursor cells. Mol Vis. 2005;11:472-481.

65. Sakamoto K, Liu C, Tosini G. Classical photoreceptors regulate melanopsin mRNA levels in the rat retina. J Neurosci. 2004;24: 9693-9697.

66. Doyle SE, Castrucci AM, McCall M, Provencio I, Menaker M. Nonvisual light responses in the Rpe65 knockout mouse: rod loss restores sensitivity to the melanopsin system. Proc Natl Acad Sci U $S$ A. 2006;103:10432-10437.

67. Semo M, Lupi D, Peirson SN, Butler JN, Foster RG. Light-induced c-fos in melanopsin retinal ganglion cells of young and aged rodless/coneless (rd/rd cl) mice. Eur J Neurosci. 2003;18:3007-3017.

68. Dacey DM, Liao HW, Peterson BB, et al. Melanopsin-expressing ganglion cells in primate retina signal colour and irradiance and project to the LGN. Nature. 2005;433:749-754.

69. Guler AD, Altimus CM, Ecker JL, Hattar S. Multiple photoreceptors contribute to nonimage-forming visual functions predominantly through melanopsin-containing retinal ganglion cells. Cold Spring Harbor Symp Quant Biol. 2007;72:509-515.

70. Sernagor E. Retinal development: second sight comes first. Curr Biol. 2005;15:R556-R559.

71. Tarttelin EE, Bellingham J, Bibb LC, et al. Expression of opsin genes early in ocular development of humans and mice. Exp Eye Res. 2003;76:393-396. 